\title{
Diet-derived transmission of MicroRNAs from host plant into honey bee Midgut
}

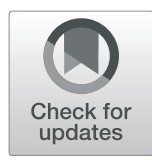

\author{
Leila Gharehdaghi', Mohammad Reza Bakhtiarizadeh², Kang He ${ }^{3}$, Taher Harkinezhad', \\ Gholamhosein Tahmasbi ${ }^{4}$ and Fei $\mathrm{Li}^{3^{*}}$
}

\begin{abstract}
Background: MicroRNA (miRNA) is a class of small noncoding RNAs, which targets on thousands of mRNA and thus plays important roles in many biological processes. It has been reported that miRNA has cross-species regulation functions between parasitoid-host, or plant-animal, etc. For example, several plant miRNAs enter into the honey bees and regulate gene expression. However, whether cross-species regulation function of miRNAs is a universal mechanism remains a debate question.

Results: We have evaluated transmission of miRNAs from sunflower and sedr plants into the midgut of honey bee using RNA-Seq analyses complemented with confirmation by RT-qPCR. The results showed that at least 11 plant miRNAs were found in the midgut of honey bee feeding by sunflower and sedr pollen. Among which, nine miRNAs, including miR-30d, miR-143, miR-148a, miR-21, let-7 g, miR-26a, miR-126, miR-27a, and miR-203, were shared between the sunflower- and sedr-fed honey bees, suggesting they might have essential roles in plant-insect interactions. Moreover, existence of these co-shared miRNAs presents a strong evidence to support the successful transmission of miRNAs into the midgut of the insect. In total, 121 honeybee mRNAs were predicted to be the target of these 11 plant-derived miRNAs. Interestingly, a sedr-derived miRNA, miR-206, targets on 53 honeybee genes. Kyoto Encyclopedia of Genes and Genome (KEGG) analyses showed that these target genes are significantly involved in hippo signaling pathway-fly, Wnt signaling pathway, and N-Glycan biosynthesis.
\end{abstract}

Conclusions: In summary, these results provide evidence of cross-species regulation function of miRNA between honeybee and flowering host plants, extending our understanding of the molecular interactions between plants and animals.

Keywords: miRNA, Cross species, Apis mellifera, Helianthus annuus, Ziziphus spina-christi

\section{Background}

MicroRNAs (miRNAs) are a class of non-coding small RNAs (sRNAs), which are functionality significant and approximately 19-24 nucleotide (nt) in size. They are known as regulators of gene expression by binding to open reading frames (ORF) or untranslated region (UTR) of specific mRNAs, targeting them for cleavage or

\footnotetext{
* Correspondence: lifei18@zju.edu.cn

${ }^{3}$ Ministry of Agriculture and Rural Affairs Key Lab of Molecular Biology of Crop Pathogens and Insects/Institute of Insect Sciences, Zhejiang University, 866 Yuhangtang Road, Hangzhou 310058, China

Full list of author information is available at the end of the article
}

directing translation inhibition at the mRNA level [1]. It has been demonstrated that around $60 \%$ of protein coding genes are targets of miRNAs and modulated by these small RNAs [2]. The miRNAs play crucial roles in a wide range of biological processes i.e. developmental timing, cell differentiation, proliferation, apoptosis as well as regulation of a number of important agronomic traits [3-7].

Recent studies revealed that miRNAs have exogenous roles as well. Plant miRNAs are 2'-O-methylated at 3' end to enhance their stability for the survival in various exogenous environments [8]. By several exogenous paths of intracellular and intercellular transport via $\mathrm{P}$ bodies

(c) The Author(s). 2021 Open Access This article is licensed under a Creative Commons Attribution 4.0 International License, which permits use, sharing, adaptation, distribution and reproduction in any medium or format, as long as you give appropriate credit to the original author(s) and the source, provide a link to the Creative Commons licence, and indicate if changes were made. The images or other third party material in this article are included in the article's Creative Commons licence, unless indicated otherwise in a credit line to the material. If material is not included in the article's Creative Commons licence and your intended use is not permitted by statutory regulation or exceeds the permitted use, you will need to obtain permission directly from the copyright holder. To view a copy of this licence, visit http://creativecommons.org/licenses/by/4.0/ The Creative Commons Public Domain Dedication waiver (http://creativecommons.org/publicdomain/zero/1.0/) applies to the data made available in this article, unless otherwise stated in a credit line to the data. 
(cytoplasmic bodies), multi vesicular bodies (MVBs) and endosomes $[9,10]$, plant miRNAs were transported into animals. The plant exogenous miRNAs find their complementary targets and modulate the transcriptional or post-transcriptional processes in animals. Cross species interactions formed by plant miRNA and host mRNA might result into genetic regulation alterations in the host [11]. Up to now, cross-species translocation of dietderived small RNAs to ingesting organisms has been described in both vertebrates [12] and invertebrates [13, 14].

It has been confirmed for the first time that plantderived miR168a could be absorbed through the gastrointestinal tract into mammalian liver cells where it inhibits the expression of the human/mouse low-density lipoprotein receptor adapter protein1 (LDLRAP1), and consequently decreases LDL removal from mouse plasma [12]. Consequently, it has been demonstrated that honeysuckle-encoded miRNAs, miR2911 could be taken up via gastrointestinal tract Influenza A virus (IAV)-infected mice and counteract viral infections [15]. As for the arthropods, a number of insects can ingest sRNAs which subsequently regulate the expression of their genes, thus reshaping the phenotype of the animal $[16,17]$. In this regard, Zhu et al. reported that plant miRNAs in larval food regulate honey bee caste development [18]. It has been shown that plant miRNAs, which are more frequent in beebread than in royal jelly, can knock out amTOR gene. This gene is linked to cast determination and decrease body and ovary size in honey bee and trigger embryo-larva transition of honeybee worker.

However, systemic uptake of orally ingested foreign miRNAs is negligible and significantly below the levels that required to be biologically relevant when acting through canonical sequence-specific miRNA-mediated mechanisms [19-21]. Hence, the hypothesis of crosskingdom regulations mediated by exogenous plant miRNAs is still controversial and remains to be clarified. As one of the well-studied pollinators, honey bee provides an excellent model for exploring the role of dietary transfer of small RNAs in communication between plants and pollinators. Though biologically relevant plant-derived miRNAs were not observed in the honey bee, further analysis showed that a highly-conserved plant miRNA, miR156a, was significantly increased in the midgut of honey bee [19]. However, there is still not direct evidence for the transmission of biologically relevant miRNAs to proximal or distal tissues of honey bees [22].

Here, we investigate the transmission of plant miRNAs from two different plant species i.e. sunflower (Order: Asterales, Family: Asteraceae) and sedr (Order: Rosales, Family: Rhamnaceae) into the midgut of honey bees under controlled environmental conditions. To detect mono-floral diet-derived miRNAs in honey bee, we chose sunflower and sedr which were the dominant vegetation in the study region in Iran and had different flowering times than the other plants. The individual honey bees are fed by either sunflower (Helianthus annuus) or sedr (Ziziphus spina-christi) pollen. Then, the total miRNAs of the midgut tissue of nurse honey bees are sequenced using RNA-Seq technology. The results show that 11 plant miRNAs are found in the midgut of nurse honey bees fed with sunflower pollen or sedr pollen. Nine out of 11 miRNAs are shared between the two groups of adult honey bees, suggesting that these miRNAs have specific features that increase their ability to transmit from the host plant to the honey bee. These data extend our understanding of cross species regulation of plant-derived miRNAs in animals.

\section{Results}

RNA-seq of sRNA libraries from sunflower and Sedr pollen To obtain an overview of the sRNAs repertories in pollen samples, four sRNA libraries were constructed in sunflower and sedr pollen. A total of 3,816,531 (SF1), 2,641,841 (SF2), 3,124,151 (Zizi1), and 1,782,133 (Zizi2) raw reads were created (Table 1). After discarding the low-quality reads, contaminated reads, $3^{\prime}$ and $5^{\prime}$ adaptors and polyA-containing sequences, 3,710,485, $2,559,080,3,074,265$ and 1,734,721 clean reads were obtained in SF1, SF2, Ziz1 and Ziz2, respectively. Subsequently, rRNAs, tRNAs, snRNAs, snoRNAs, low complexity sequences and sequences smaller than $16 \mathrm{nt}$ and longer than $30 \mathrm{nt}$ were filtered, yielding 2,530,144 (SF1), 1,803,175 (SF2), 1,962,507 (Zizi1), and 1,182,018 (Zizi2) clean reads, respectively (Fig. 1; Table 1). The length of pollen sRNAs ranged from 16 to $30 \mathrm{nt}$, while in sunflower samples $22 \mathrm{nt}$ sRNAs had the highest proportion followed by $24 \mathrm{nt}$ sRNAs (Fig. 2B). In sedr samples $24 \mathrm{nt}$ sRNAs had the largest number, followed by 22 nt sRNAs (Fig. 2A).

\section{Known and novel miRNAs in sunflower and Sedr pollen}

In order to identify miRNAs in sunflower and sedr pollen samples, the clean sRNA reads were aligned against the miRBase database. In sunflower, a total of 106,904 and 29,186 reads from two samples were mapped to miRBase, which resulted in the identification of 495 shared miRNAs in two samples (Table 1). The identified miRNAs in sunflower were belonged to 409 miRNA families. Among the detected miRNAs, 355 miRNA families consisted of one member; 38 miRNA families consist of two members; seven miRNAs including miR-139, miR-223, miR-24, miR-7386, miR-92, miR7398 and miR-29 had three members; four miRNAs including miR-11,108, miR-7385, miR-3851 and miR11,619 had four members, and three miRNAs including 
Table 1 Statistics of small RNA sequences in sunflower and sedar pollen samples

\begin{tabular}{|c|c|c|c|c|}
\hline Types & SF1 & SF2 & Zizi1 & Zizi2 \\
\hline Raw reads & $3,816,531$ & $2,641,841$ & $3,124,151$ & $1,782,133$ \\
\hline Clean reads & $3,710,485$ & $2,559,080$ & $3,074,265$ & $1,734,721$ \\
\hline rRNA & 679,142 & 365,507 & 283,842 & 225,353 \\
\hline tRNA & 106,238 & 106,852 & 745,454 & 275,339 \\
\hline snRNA & 1001 & 1439 & 1297 & 735 \\
\hline snoRNA & 965 & 591 & 227 & 224 \\
\hline Law Complexity reads & 1677 & 883 & 1526 & 2301 \\
\hline miRNAs & 3733 & 1567 & 29,338 & 41,736 \\
\hline Others & $1,120,901$ & 739,670 & 307,581 & 303,214 \\
\hline Contaminated reads & 133 & 67 & 61 & 90 \\
\hline No annotation & $1,405,511$ & $1,061,938$ & $1,625,588$ & 837,068 \\
\hline Reads after the removal of other small RNAs & $2,530,144$ & $1,803,175$ & $1,962,507$ & $1,182,018$ \\
\hline Aligned reads against known mature plant miRNAs & 106,904 & 29,186 & 47,478 & 67,393 \\
\hline Known miRNAs & 866 & 495 & 423 & 773 \\
\hline
\end{tabular}

miR-166, miR-159 and let-7 had five members. Two largest family, miR-156 and miR-482, had six members (Fig. 3(A), Additional file 1: Table S1).

In sedr pollen samples, a total of 47,478 and 67,393 reads from two samples were mapped to miRBase, which resulted in the identification of 423 shared miRNAs in two samples. In this case, 368 miRNA families were found which 329 miRNA families consisted of one member and 31 miRNA families consist of two miRNAs. Further, miR-396, miR-7398, miR-6016, miR-279 and miR-11,619 had three members, miR-3851 had four members, let-7 had six members and the largest family belongs to miR-482 with seven members (Fig. 3(B), Additional file 2: Table S2). The size of known miRNAs varied from 17 and $28 \mathrm{nt}$ with $22 \mathrm{nt}$ as the peak, followed by $21 \mathrm{nt}$ in both the studied plants.

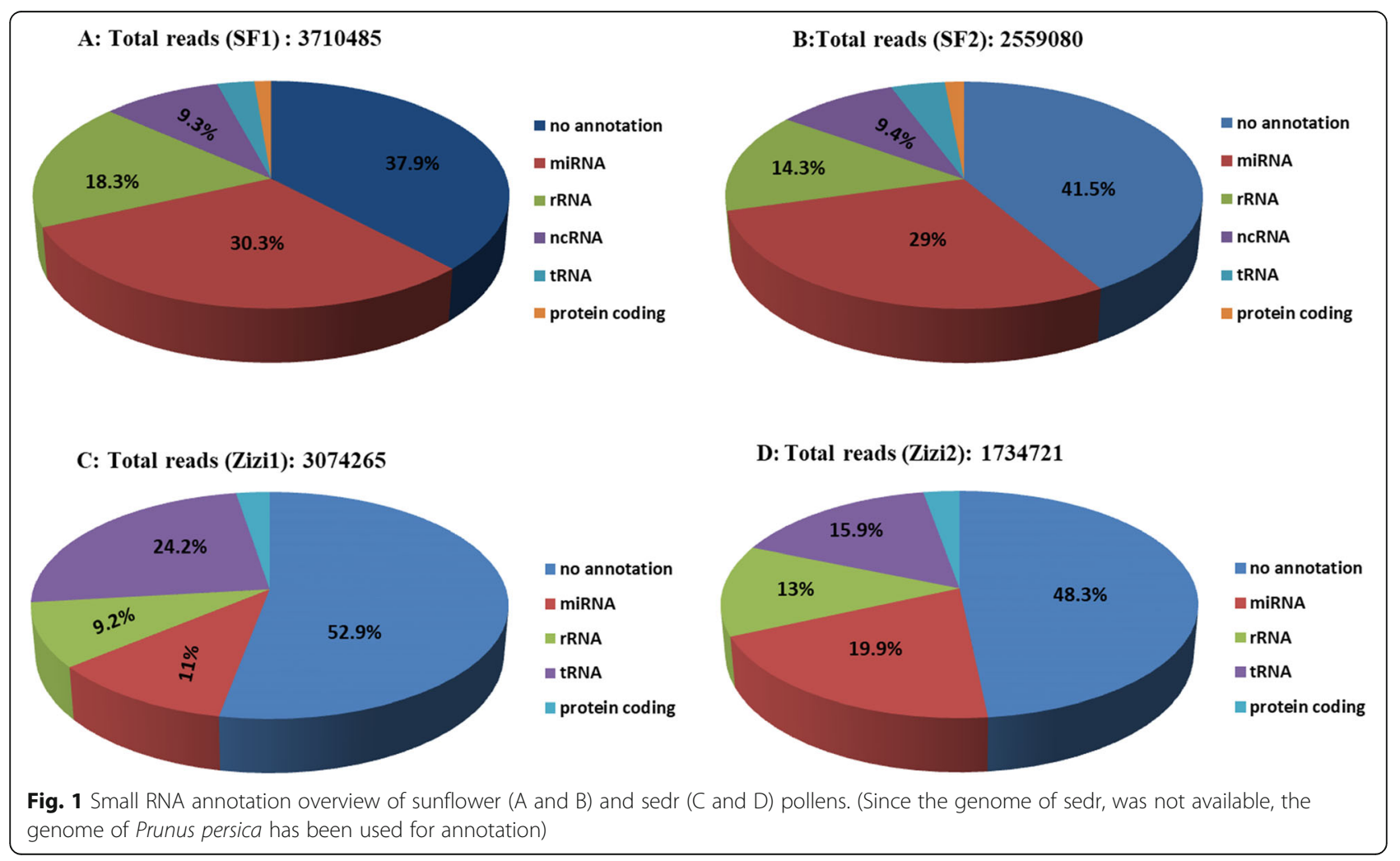




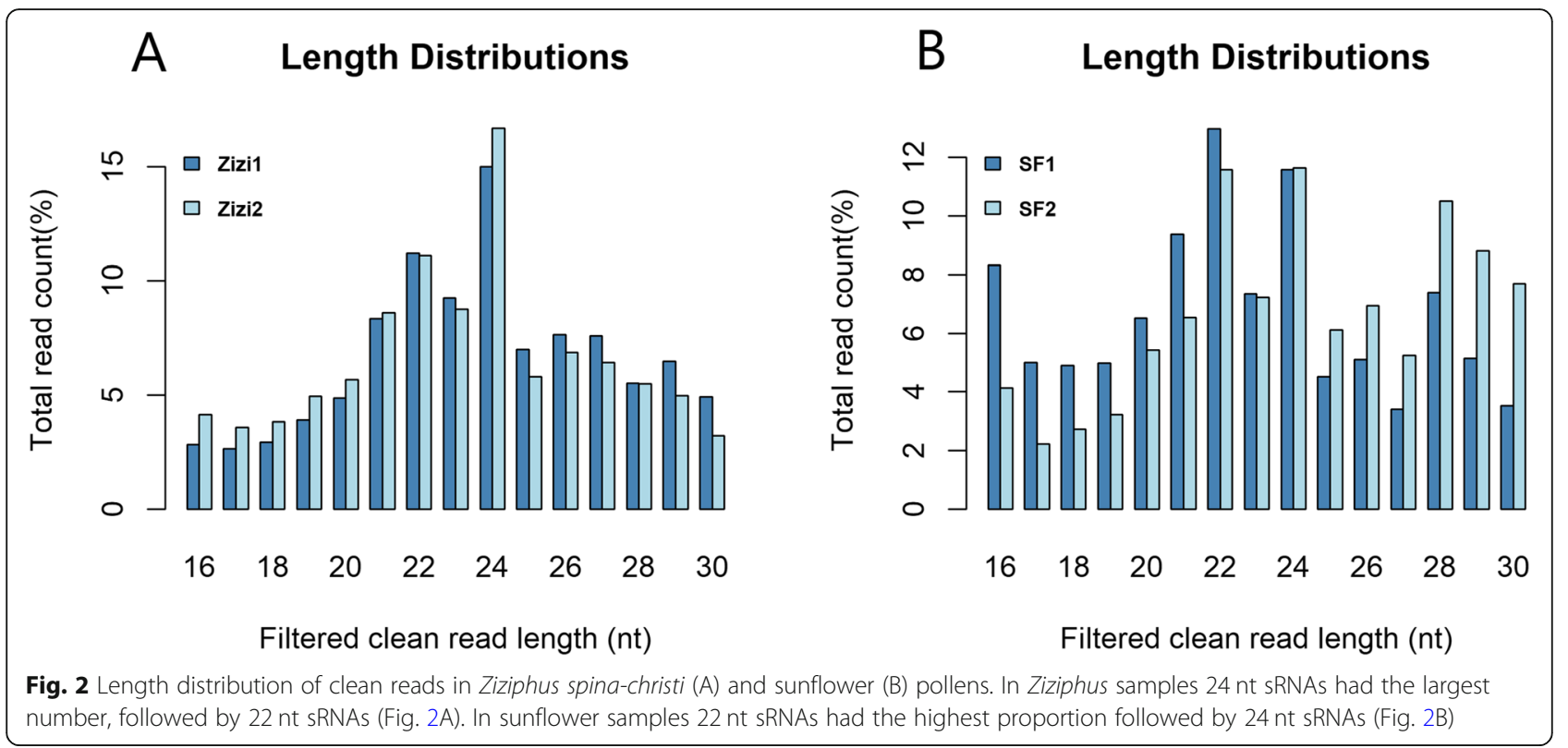

In addition, novel miRNAs were predicted using miRDeep-P2 software with one mismatch allowed in sunflower pollen. The mapped reads were extended to obtain precursor sequences which were further folded into potential stem-loop structures using Vienna package. The resulted miRNA precursor structures that were represented by less than 10 reads were excluded and a final set of 16 novel miRNAs were predicted (belonging to 10 families and named as Han-novel-miR100 to Han-novel-miR110). The size of novel miRNAs ranged from 20 to $22 \mathrm{nt}$, while the most of them were $21 \mathrm{nt}$ in length (Additional file 3: Table S3). It has been noted that low free energy is one of the major characteristics of miRNAs [23]. In sedr, unaligned reads to miRBase were subjected to novel miRNAs prediction using Mirnovo software. The list of the identified novel miRNAs, their consensus sequences and coverage features are presented in Additional file 4: Table S4 for sedr plant.

\section{Diet-derived miRNAs in honey bee Midgut}

Six sRNA samples were generated from the RNA purified from midgut of honey bee fed with sunflower (two samples) or sedr pollen (two samples). The honey bee

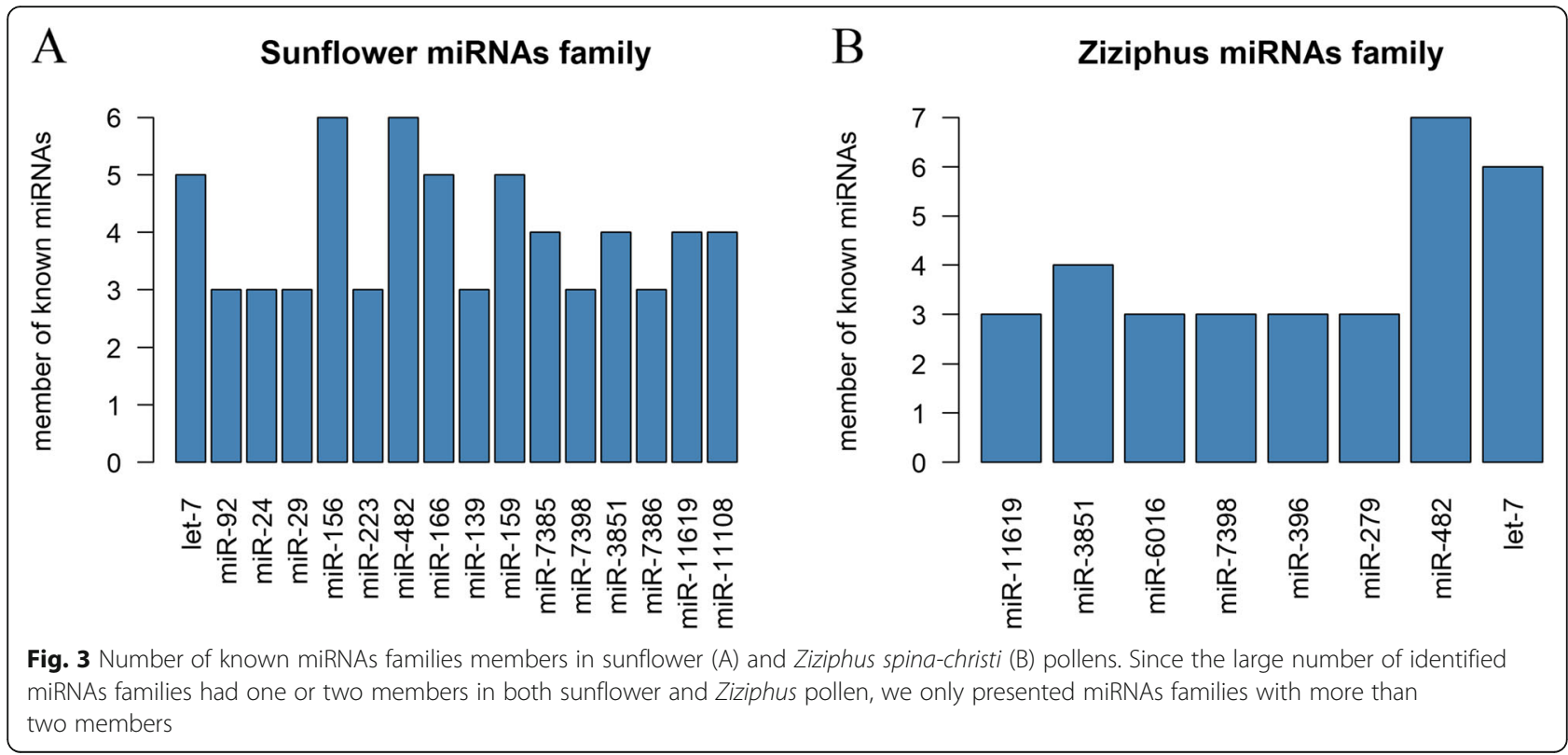


fed with sugar syrup was used as the control group (two samples). A total of 2,030,142 (T1-SF), 3,975,267 (T2SF), 2,237,955 (T1-Zizi), 2,238,200 (T2-Zizi2), 2,660,260 (control1) and 4,251,505 (control2) raw reads were produced (Table 2). After removing rRNAs, tRNAs, snRNAs, snoRNAs and low complexity sequences (Fig. 4; Table 2), the remaining reads were aligned against all insect mature miRNAs from miRBase. Subsequently, unaligned reads were mapped against Apis mellifera genome to remove any putative miRNA sequences from honeybee. Finally, 396,963 (T1-SF), 877,506 (T2-SF), 772,823 (T1-Zizi), 597,489 (T2-Zizi), 390,800 (control1) and 466,808 (control2) reads were used for alignment against identified plant miRNAs (Table 2).

The resulting reads from sunflower- and sedr-treated honey bee samples were aligned against identified sunflower miRNAs (495 known miRNAs and 16 novel miRNAs) and sedr miRNAs (423 known and nine novel miRNAs). As a result, 4520 (T1-SF), 10,632 (T2-SF), 5670 (T1-Zizi) and 4100 (T2-Zizi) reads were aligned to identified miRNAs, which led to detection of 11 (T1-SF), 31 (T2-SF), 15 (T1-Zizi) and 11 (T2-Zizi) miRNAs in the treated groups (Table 2). The miRNAs that were detected in both biological replications of each treatment were kept for further analysis. Interestingly, all the identified miRNAs (11 miRNAs in each group) were detected in both biological replications in both plants. Of these miRNAs, nine miRNAs i.e. miR-148a-3p, miR-26a, miR21-5p, miR-143, miR-27a, miR-203, let-7 g, miR-126, and miR-30d exist in both two groups (honey bee fed with sunflower and sedr pollen). The miR-101 and miR103 were only detected in honey bees fed with sunflower, while miR-199b-3p and miR-206 were found in honey bees treated with sedr pollen (Additional file 5: Table S5). The sequences of the control group of honey bees were also aligned against identified sunflower and sedr miRNAs. Fifty-six (control1) and 73 (control2) reads were aligned with sunflower miRNAs and 45 (control1) and 69 (control2) reads were aligned with sedr miRNAs. No common miRNA was found between the control and treated groups.

\section{Detection of miRNAs using RT-qPCR}

In order to validate the existence of the identified miRNAs in the midgut, nine miRNAs including miR-30d, miR-143, miR-103, miR-21-5p, let-7 g, miR-26a, miR126, miR-148a and miR-206 were investigated using RTqPCR. The expression patterns of six miRNAs including let-7 g, miR-21-5-p, miR-126, miR-26a, miR-148a and miR-206 were consistent between RT-qPCR and RNASeq (Fig. 5). However, the expression patterns of three miRNAs including miR-30d, miR-143 and miR-103 were not consistent between RT-qPCR and RNA-seq. (Fig. 5). Out of seven shared miRNAs between the two treated groups, there was no amplification in control samples in five miRNAs i.e. miR-21-5p, let-7 g, miR-26a, miR-126, and miR-148a-3p, while in the treated samples all the five miRNAs were expressed. Two miRNAs including

Table 2 Statistics of small RNA sequences in pollen-treated and control honey bees for detection of diet-derived sunflower and Sedar miRNAs

\begin{tabular}{|c|c|c|c|c|c|c|}
\hline Types & Control1 & Control2 & T1_SF & T2_SF & T1_Zizi & T2_Zizi \\
\hline Raw reads & $2,660,260$ & $4,251,505$ & $2,030,142$ & $3,975,267$ & $2,237,955$ & $2,238,200$ \\
\hline Clean reads & $2,558,916$ & $4,093,244$ & $1,696,697$ & $3,449,599$ & $2,077,808$ & $2,172,285$ \\
\hline rRNA & $1,096,486$ & $1,336,965$ & 642,603 & $1,079,158$ & 439,323 & 681,660 \\
\hline tRNA & 68,118 & 108,148 & 144,150 & 319,453 & 187,744 & 169,690 \\
\hline snRNA & 40,226 & 27,042 & 16,751 & 39,478 & 14,056 & 15,065 \\
\hline snoRNA & 5071 & 4814 & 2920 & 6974 & 2945 & 3504 \\
\hline Law complexity reads & 4176 & 10,068 & 1414 & 3269 & 1263 & 1991 \\
\hline Contaminated reads & 938 & 4651 & 505 & 850 & 623 & 598 \\
\hline Reads related to Apis mellifera miRNAs & 111,446 & 573,125 & 65,904 & 140,928 & 79,284 & 124,621 \\
\hline Reads related to other insect miRNAs & 3097 & 21,525 & 1483 & 2899 & 1413 & 1685 \\
\hline No annotation reads & 801,690 & $1,202,178$ & 623,295 & $1,421,167$ & $1,071,775$ & 887,345 \\
\hline Reads after removal of other small RNAs and all insect miRNAs & 801,690 & $1,202,178$ & 623,295 & $1,421,167$ & $1,071,775$ & 887,345 \\
\hline Reads mapped against Apis mellifera genome & 410,890 & 735,370 & 226,332 & 543,661 & 298,952 & 289,856 \\
\hline Reads unmapped against Apis mellifera genome & 390,800 & 466,808 & 396,963 & 877,506 & 772,823 & 597,489 \\
\hline Aligned reads to SF_miRNAs & 56 & 73 & 4520 & 10,632 & - & - \\
\hline Aligned reads to Zizi_miRNAs & 45 & 69 & - & - & 5670 & 4100 \\
\hline Count of the detected miRNAs of SF & 0 & 0 & 11 & 31 & - & - \\
\hline Count of the detected miRNAs of Zizi & 0 & 0 & - & - & 15 & 11 \\
\hline
\end{tabular}




\section{sRNA annotation for honey bee samples}

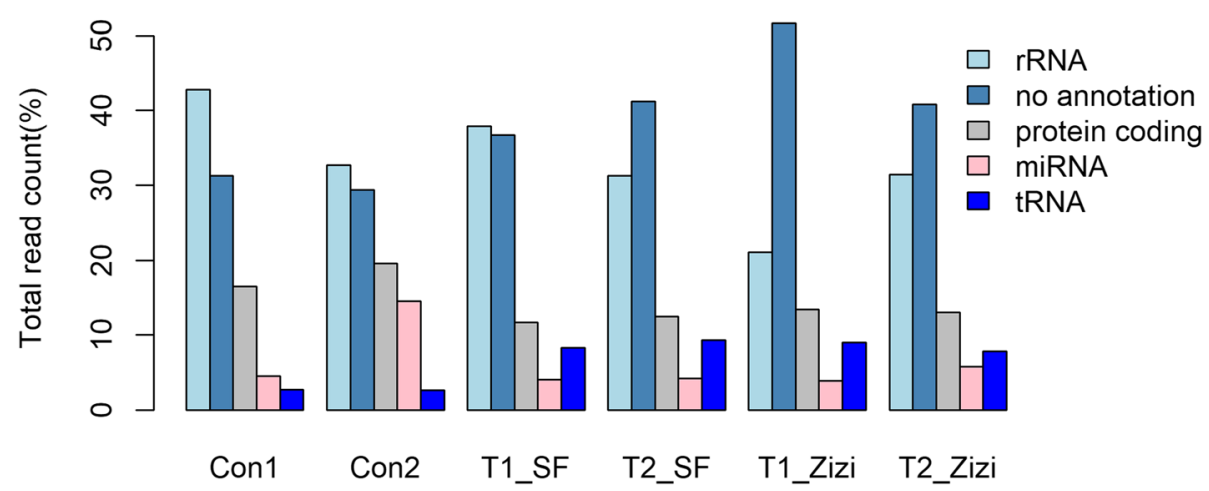

Fig. 4 Small RNA annotation of six honey bee samples: T1_SF and T2_SF: honey bees fed with sunflower pollens. T1_Zizi and T2_Zizi: honey bees fed with sedr pollen, and control1 and control2 honey bees fed by sugar syrup

let-7 $\mathrm{g}$ and miR-26a were highly expressed in sunflowertreated honey bees than sedr treated groups. (Student ttest, $p<0.05)$. However, the expressions of three miRNAs including miR-21-5p, miR-126 and miR-148a-3p were similar between sunflower and sedr treated groups. In the case of miR-143 and miR-30d, extension was observed in the control group in addition to the treated groups. On the other hand, miR-206 was expressed in sedr treatment but not in the control group, while miR-103 was expressed in both the control and sunflower treatment. For the three miRNAs that were expressed in control group even more than the treated groups fold change parameter was calculated. The expression of miR-30d, miR-143 and miR-103 in the treated groups showed a significant difference in comparison to the control sample. The lower expression of the three miRNAs in the control group might be due to the differences in feeding (lower feeding) of the honey bees inside the colony.

\section{Target prediction and potential function of individual miRNAs}

In total, 121 target genes were predicted for the 11 dietderived plant miRNAs. Only one target was predicted for miR-203 and miR-101, while $21,11,8,7,7,6,4$ and

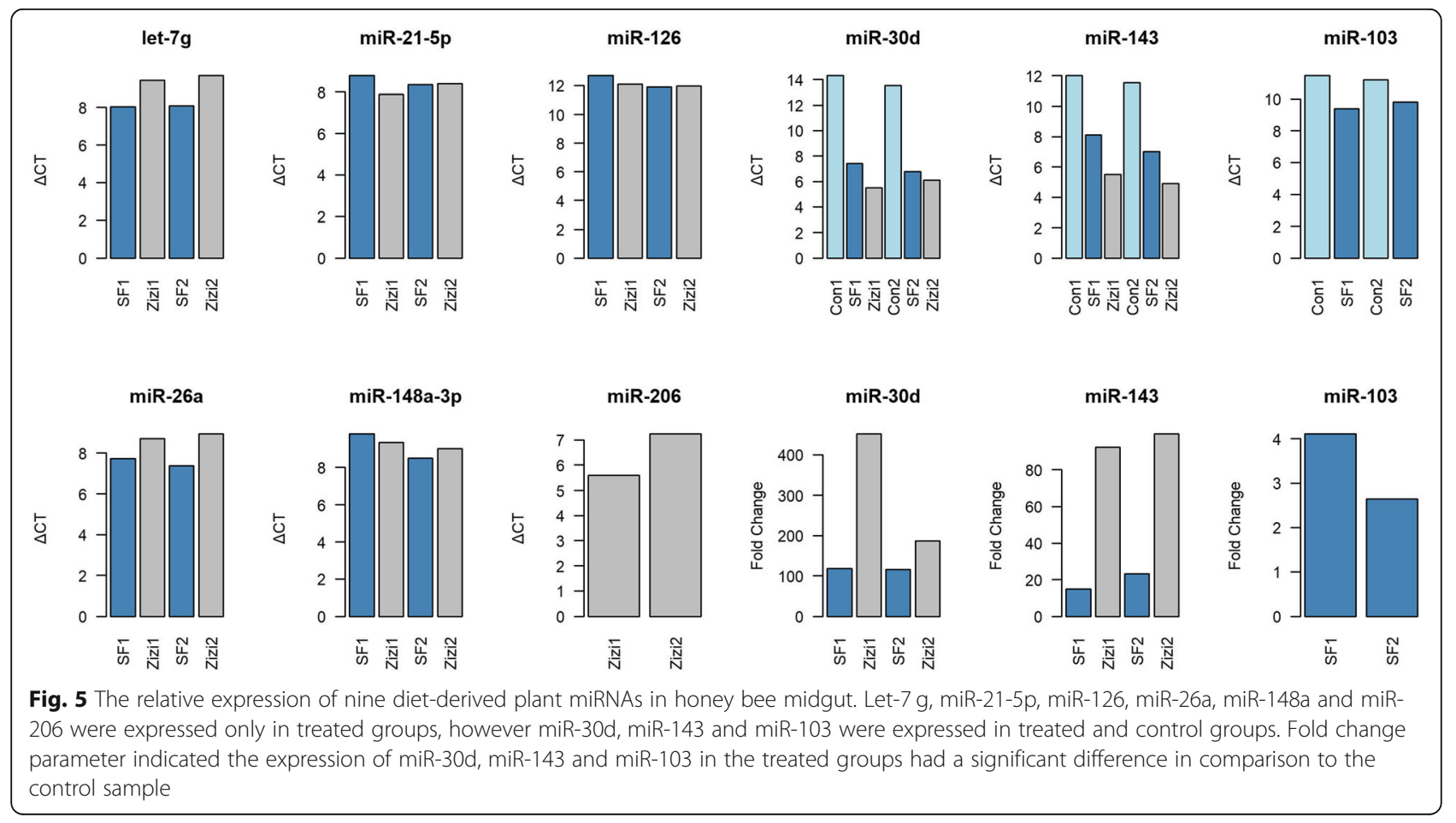


2 target genes were predicted for miR-103, let-7 g, miR143, miR-199b, miR-126, miR-27a, miR-26 and miR-30d, respectively. The miR-206 had the highest number of targets with 53 predicted genes (Additional file 6: Table S6) and no taget gene was detected for miR-148a and miR-21-5p.

To shed a light on the potential function of the target genes of transmitted plant miRNAs, KEGG pathway analysis was performed. Totally, 25 pathways related to eight diet-derived miRNAs were significantly enriched (Table 3). The exogenous let-7 $\mathrm{g}$ targets were significantly enriched in Wnt signaling pathway such as Palmitoleoyl-Protein Carboxylesterase NOTUM (LOC107963993) and Palmitoleoyl-Protein Carboxylesterase NOTUM-like (LOC552168) (Fig. 6). Wnt signaling is one of the most crucial morphogens for development and associated with the establishment and maintenance of synaptic structural and neuronal function during the maturation of the central nervous system [25]. The other important target genes of let-7 are Lethal (2) giant larvae protein homolog 1 (LOC409348), which is involved in hippo signaling pathway (Fig. 7). Hippo signaling pathway is an evolutionarily conserved signaling pathway that plays an important role in the control of organ growth and development [26]. Interestingly, previous study in honey bee revealed that development of morphological differences among honey bee castes require a complex fine-tuning of hippo signaling pathway by miRNAs and DNA methylation [17]. Pyruvate carboxylase (LOC412876) is the other predicted target gene by exogenous let-7. This gene is involved in pyruvate metabolism, citrate cycle (TCA cycle), biosynthesis of amino acids and carbon metabolism. Also, phosphatidylinositol 4-kinase type 2 (GB50211) was predicted to be targeted by exogenous let-7. This gene plays important roles in Inositol phosphate metabolism and phosphatidylinositol signaling pathways. N-Glycan biosynthesis pathway was identified to be enriched by the target genes of miR-26a. The pathways associated with protein biosynthesis and lipid metabolism as well as glycan biosynthesis and metabolism [N-glycan biosynthesis and Glycosylphosphatidylinositol (GPI)-anchor

Table 3 Significant KEGG pathways in the target genes of the detected diet-derived plant miRNAs

\begin{tabular}{|c|c|c|c|c|}
\hline miRNAs & PATHWAY & Gene Name & $P$-Value & Corrected-P-Value \\
\hline \multirow[t]{8}{*}{ Let-7 g } & ame04310:Wnt signaling pathway & GB54903, GB49269 & $1.70 \mathrm{e}-3$ & $1.53 e-2$ \\
\hline & ame00620:Pyruvate metabolism & GB40280 & $2.95 e-2$ & $5.94 \mathrm{e}-2$ \\
\hline & ame00020: Citrate cycle (TCA cycle) & GB40280 & $3.22 \mathrm{e}-2$ & $5.94 \mathrm{e}-2$ \\
\hline & ame00562: Inositol phosphate metabolism & GB50211 & $4.27 e-2$ & $5.94 \mathrm{e}-2$ \\
\hline & ame04070:Phosphatidylinositol signaling & GB50211 & $4.62 \mathrm{e}-2$ & $5.94 \mathrm{e}-2$ \\
\hline & ame04391:Hippo signaling pathway-fly & GB55164 & $4.62 \mathrm{e}-2$ & $5.94 \mathrm{e}-2$ \\
\hline & ame01230:Biosynthesis of amino acids & GB40280 & $4.62 \mathrm{e}-2$ & $5.94 \mathrm{e}-2$ \\
\hline & ame01200: Carbon metabolism & GB40280 & $8.030 \mathrm{e}-2$ & $9.04 \mathrm{e}-2$ \\
\hline \multirow[t]{7}{*}{ miR-126 } & ame00830:Retinol metabolism & GB53086 & $3.95 e-3$ & $1.18 \mathrm{e}-2$ \\
\hline & ame00350: Tyrosine metabolism & GB53086 & $4.94 \mathrm{e}-3$ & $1.18 \mathrm{e}-2$ \\
\hline & ame00982:Drug metabolism-cytochrome P450 & GB53086 & $5.27 e-3$ & $1.18-2$ \\
\hline & ame00980:Metabolism of xenobiotics by cytochrome P450 & GB53086 & $5.92 \mathrm{e}-3$ & $1.18 \mathrm{e}-2$ \\
\hline & ame00071:Fatty acid degradation & GB53086 & $8.22 \mathrm{e}-3$ & $1.32 \mathrm{e}-2$ \\
\hline & ame00010: Glycolysis Gluconeogenesis & GB53086 & $1.41 \mathrm{e}-2$ & $1.88 \mathrm{e}-2$ \\
\hline & ame01200: Carbon metabolism & GB53086 & $3.00 \mathrm{e}-2$ & $3.43 e-2$ \\
\hline miR-143 & ame00970:Aminoacyl-tRNA biosynthesis & GB40563 & $1.68 \mathrm{e}-2$ & $1.68 \mathrm{e}-2$ \\
\hline \multirow[t]{2}{*}{ miR-103 } & ame04512:ECM-receptor interaction & GB45968 & $2.77 e-2$ & $3.99 e-2$ \\
\hline & ame04933:AGE-RAGE signaling pathway in complications & GB45968 & $3.99 e-2$ & $3.99 e-2$ \\
\hline \multirow[t]{2}{*}{ miR-199 } & ame03040-Spliceosome & GB52855 & $3.42 \mathrm{e}-2$ & $3.71 e-2$ \\
\hline & ame04141:Protein processing in endoplasmic reticulum & GB41586 & $3.71 \mathrm{e}-2$ & $3.71 e-2$ \\
\hline miR-26a & ame00510:N-Glycan biosynthesis & GB54846 & $5.77 e-3$ & $5.77 e-3$ \\
\hline \multirow[t]{2}{*}{ miR-203 } & ame00230:Purin metabolism & GB44602 & $6.19 e-3$ & $1.24 \mathrm{e}-2$ \\
\hline & ame01100:Metabolic pathways & GB44602 & $6.70 \mathrm{e}-2$ & $6.70 \mathrm{e}-2$ \\
\hline \multirow[t]{2}{*}{ miR-27a } & ame04145:Phagosome & GB54140 & $9.87 e-3$ & $1.82 \mathrm{e}-2$ \\
\hline & ame04144:Endocytosis & GB54140 & $1.82 \mathrm{e}-2$ & $1.82 \mathrm{e}-2$ \\
\hline
\end{tabular}




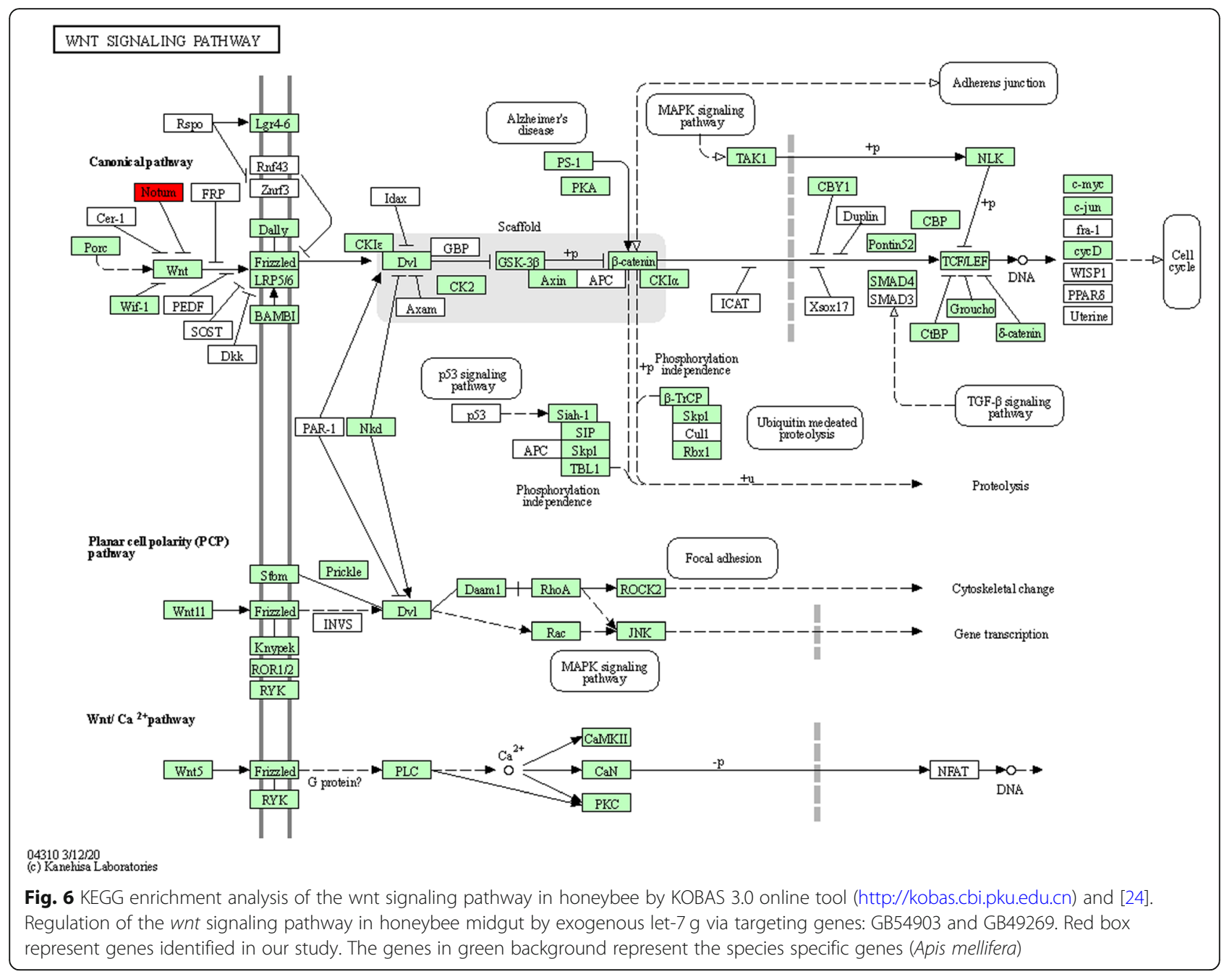

biosynthesis] are important for active nurse bees to synthesize the major protein components of royal jelly and secrete the lipid-rich components to the brood [27]. Hepatocyte growth factor-regulated tyrosine kinase substrate (Gene Hrs) was predicted to be targeted by exogenous miR-27a and is involved in endocytosis and phagosome pathways. Hrs plays a key role in the invagination of the endosome membrane and the formation of multi-vesicular bodies (MVBs). Hrs appeared to be essential during gastrulation and regulated early embryonic signaling pathways. Furthermore, Hrs may inhibit tyrosine kinase receptor signaling by promoting tyrosine phosphorylate degradation of the active receptor, potentially through sorting activated receptors into MVBs. Seven genes were identified as targets of miR-126 and were significantly enriched in seven different pathways including: retinol metabolism, tyrosine metabolism, drug metabolism-cytochrome P450, metabolism of xenbiotics by cytochrome $\mathrm{P} 450$, fatty acid degradation, glycolysis gluconeogenesis and carbon metabolism pathways. One of the target genes is Fdh (S-(hydroxymethyl) glutathione dehydrogenase) with catalytic activity. Our results indicated that miR-103 is capable of targeting collagen alpha-1(IV) chain (LOC408552), which is involved in ECM-receptor interaction pathway in the honey bee. Previously, it has been shown that the ECMreceptor interaction pathway is related to high royal jelly production in the honey bee [28]. One of the most important potential target genes of miR-199 was Signal sequence receptor subunit gamma (LOC552295), which acts as TRAP proteins. This gene binds calcium to the endoplasmic reticulum (ER) membrane and thereby regulates the retention of ER resident proteins. Interestingly, it has been reported that divergent forms of endoplasmic reticulum stress generate a strong unfolded protein response in honey bees [29]. In the present study, bioinformatics analysis indicated exogenous miR206 had the highest number of targets with 53 predicted genes. Enrichment analyses of miR-206 target genes indicated target genes participated in 21 different pathways while none of the identified pathways was significant (Additional file 7: Table S7). All these findings will 


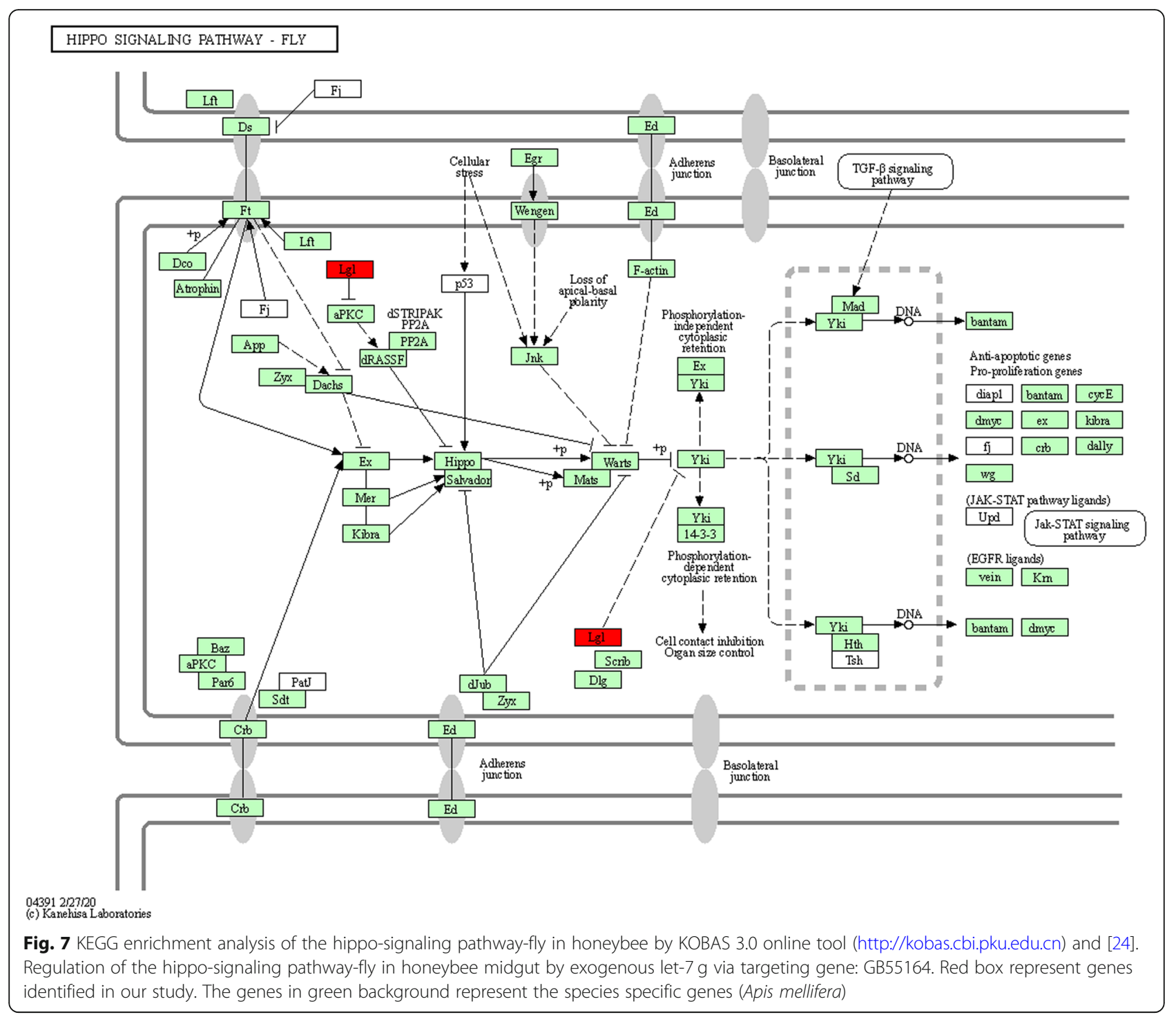

extend our understanding of the molecular interactions between honey bee and flowering host plants.

\section{Discussion}

Recent study supports evidence which movement of small RNA molecules (siRNA and miRNA) between species may play a key role for the dissemination of genesilencing signals and the promotion of cross-talk between different organisms [30]. Taken together, the mobility of small RNAs from one species to another has been broadly supported from bacteria to nematodes [31], from fungal pathogens to plants [32], from plants to pathogenic and symbiotic microbes [33-36], from plants to nematodes [37] and from plants to vertebrates [12, 15].

Diet-derived transmission of miRNAs from host plant into the midgut of honey bees was evaluated under environmentally controlled conditions. It has noted that horizontal transmission of miRNAs to recipient honey bees is negligible [22]. They investigated transmission of miR-156a, the highly conserved plant miRNAs in pollen in different tissues of honey bees in different life stages of the insect. Though they have observed robust increase of plant miRNAs in the midgut tissue after pollen ingestion, they found no evidence of biologically relevant function for delivery of these molecules to proximal or distal tissues of recipient honey bees. However, our work presented evidence that a number of plant miRNAs were successfully transmitted to the midgut of honey bee. We showed that the transmission of diet-derived plant miRNAs into adult honey bee midgut tissue under controlled pollen feeding conditions. This is the first comprehensive study confirming the transmission of miRNAs from the host plant into honey bees.

The let-7 miRNA was one of the first miRNAs discovered in the nematode Caenorhabditis elegans [38], which is involved in various developmental processes as shown 
in Bombyx mori and Drosophila melanogaster [39, 40]. Previous studies in honey bee demonstrated that Let-7 is one of the few consistent miRNA markers associated with the behavioral shift of worker bees from nurses to foragers [41-43]. Recently bioinformatics analysis has suggested that Wnt signaling pathway play a critical role in honey bee behavioural maturation [44]. To determine the relationship between honey bee nursing performance and neurobiological activities, phosphoproteom investigation in nurse honey bee brains revealed that phosphatidylinositol signaling pathway, inositol phosphate metabolism and Wnt signaling pathways are required for brain maturation, development, signal transduction and the olfactory learning processes during the early stages of worker life to enhance their nursing task performance [45]. This finding may reinforce the results of our study that enriched Wnt signaling pathway, phosphatidylinositol signaling pathway and inositol phosphate metabolism in the exogenous let-7 genes target may be involved in the modulation of honey bee behavior by regulating the neuronal function of the honey bee brain. However more comprehensive studies are needed to prove the the role of exogenous let-7 target genes in honey bee nursing task performance. miR-143 is known as a multi-functional miRNA. Predicted target genes by exogenous miR-143 were significantly enriched in aminoacyl-tRNA biosynthesis pathway. Previously, the role of aminoacy-tRNA biosynthesis pathway in processing of materials of nascent peptides for protein synthesis in honey bee ( $48 \mathrm{~h}$ embryos) has been indicated [46] However, further works are required to illustrate the role of exogenous miR-143 target genes for protein synthesis in honeybee.

Phagocytosis is related to cellular immune pathway in insects [47]. Previously over-representation of phagosome formation pathway has been observed in nurse honey bees when compared to forager bees [27]. Overrepresentation of this pathway in nurse honey bees can be led to enhance the immune activity in nurses, which is necessary to brood care. This finding is consistent with our result that suggested target genes by exogenous miR-27 were significantly enriched in phagosome pathway in nurse honey bee. However, further investigations are required to elucidate the roles of exogenous miR-27 target genes in immune pathway. The other enriched pathway by exogenous miR-27 was endocytosis, which may be involved in honey bee antiviral defense [48]. miR-206, is one of the interesting miRNAs characterized in our study which has a significant effect on the dynamic mechanism of the mammalian circadian rhythms occurring with a periodicity close to $24 \mathrm{~h}$ in almost all living organisms from the cyanobacteria to plants, insects and mammals [49]. Although it has not yet been mentioned the role of miR-206 in controlling the circadian clock of insects, the results of present study may be a helpful step to evaluate this idea.

\section{Conclusions}

We demonstrate that plant miRNAs could be transmitted into the midgut of honey bee upon the insect feeding on pollen. Our findings also revealed the lack of obvious differences between miRNAs originated from sunflower and sedr pollen, although some unique miRNAs for each of the host plants were detected in the insect body. We also determined the target genes for all the miRNAs with plant origin in the midgut of honey bee. KEGG analyses proposed the involvement of the target genes in different pathways that may help establish the conditions for a compatible interaction. Our results revealed many candidate genes which could be involved in the transmission and compatibility of plant miRNAs into the midgut of honey bee that may be potentially useful for engineering molecular aspects of pollinator insects in the twenty-first century's agriculture. Finally, based on the findings of present study, it is suggested that the probability of plant miRNAs being transferred from nurse bees to larvae during feeding be explored further in the future.

\section{Methods}

\section{Honey bee and pollen collection}

A healthy honey bee (Apis mellifera meda) colony with no symptoms of common bacterial, fungal and viral diseases was settled next to a sunflower farm in Shal County of Qazvin province (located in central of Iran) in September 2018, when $\% 80>$ of the plants were in flowering stage. A similar colony was settled next to a wide area of sedr trees in Jiroft County of Kerman province (located in south of Iran), during their flowering stage in October 2018. Pollen was collected from corbiculae of returning forager bees using pollen trap device and immediately transferred into a fluid nitrogen tank.

\section{Feeding treatments}

For feeding experiment, nurse bees that pushed their heads in older larval cells for at least $3 \mathrm{~s}$, were collected using mouth aspirator. In brief, about a hundred young nurse bees, ranging in age from three to 6 days, were transferred to each cage. Bees from two replicate of each treatment were collected from the same colony. The outer dimensions of the cages were $15 \times 11 \times 15 \mathrm{~cm}$. Except for the front portion; the cages were entirely made of wood. The front of the cages was made of 8-mesh screen (screen cell opening were $1.5 \mathrm{~mm}$ wide). The top of the cages had two holes where feeding tubes could be inserted. Within the cages for resting bees, a small empty comb was attached. The bees were placed inside the cages by sliding one side of the cages. The cages 
were placed inside the hives to maintain natural conditions including Queen Mandibular Phermone (QMP), humidity, as well as temperature, and metal mesh nets with $1 \mathrm{~mm}$ holes were used to separate the hive from the cages. All the bee groups were fed with a diet of sugar syrup for $48 \mathrm{~h}$, starved for $3 \mathrm{~h}$ to encourage feeding, and then two cages were fed with $30 \%$ sucrose + sunflower pollen at a concentration of $50 \mathrm{mg} / \mathrm{ml}$, two cages were fed with $30 \%$ sucrose + sedr pollen and the other two cages were fed with sucrose syrup without pollen as a control group for $24 \mathrm{~h}$. After a cold anesthesia, honey bee midgut tissues were aseptically removed from abdomens for further analyses. The food bolus was removed from the midgut of treatment group by sliding out the peritrophic matrix as 1 or 2 discrete sacs with a sterile scalplel, along with its contents. All the collected midgut samples as well as the pollen samples used for feeding, were resolved in Trizol (Invitrogen) and stored at $80^{\circ} \mathrm{C}$ to be used for total RNA extraction.

\section{RNA extraction and sequencing}

Total RNA from sunflower, sedr pollens and honey bee midgut tissues including those fed by sunflower and sedr pollen as well as the control bees fed by sugar syrup (two replicates per treatment, named: SF1, SF2, Zizi1, Zizi2, T1-SF, T2-SF, T1-Zizi, T2-Zizi, Con1 and Con2 respectively) was extracted using miRNeasy mini Kit (Qiagen, Valencia, CA, USA) with a phenol-chloroform column-based extraction method as previously described by [22]. The quality and contamination of the RNAs were monitored on $1 \%$ agarose gel. Furthermore, RNA purity was checked using the NanoPhotometer ${ }^{\circ}$ spectrophotometer (IMPLEN, CA, USA), while the concentration was measured using Qubit $^{\circ}$ RNA Assay Kit in Qubit $^{\oplus}$ 2.0 Flurometer (Life Technologies, CA, USA). RNA integrity was also assessed using the RNA Nano 6000 Assay Kit of the Agilent Bioanalyzer 2100 system (Agilent Technologies, CA, USA). The cDNA libraries were generated using NEBNext ${ }^{\circ}$ Multiplex Small RNA Library Prep Set for Illumina ${ }^{\circ}$ (NEB, USA) and were clustered using TruSeq SR Cluster Kit v3-cBot-HS according to the manufacturer's instructions. They then were subjected to sequencing on an Illumina Hiseq 2500/2000 platform and $50 \mathrm{bp}$ single-end reads at Novogene (HK) Company- Beijing, China (https://en. novogene.com/). The sequencing results were deposited in the NCBI SRA database under the project PRJNA695090.

\section{MiRNA identification}

Briefly, clean reads were obtained after discarding adapters, poly- $\mathrm{N}$ sequences, and low quality reads smaller than $16 \mathrm{nt}$ or longer than $30 \mathrm{nt}$. The clean Reads were aligned to a collection of Silva, GtRNAdb, Rfam, and Repbase databases to filter ribosomal RNAs (rRNA), transfer RNAs (tRNA), small nuclear RNAs (snRNA), small nucleolar RNAs (snoRNA), repeat sequences and other ncRNAs using Bowtie tool (v1.1.2) [50]. Since the genome of sedr was not available, the genome of Prunus persica (accession number: GCA_000346465) was used for annotation. The resulted clean reads were used to detect known miRNAs, in sunflower and sedr pollens, through comparing them against plant mature miRNAs from miRBase Release 22 (http://www.mirbase.org) using Bowtie alignment tool (v1.1.2) with one mismatch. Then, unaligned unique reads were applied to identify novel miRNAs in in sunflower and sedr pollens separately. RNAFold tools [51] were used to predict the secondary structure of all the novel miRNAs. miRDeep-P2 (v1.1.3) software [52], with one mismatch allowed was used to predict the novel miRNAs in the unaligned unique reads of sunflower samples. The novel miRNAs prediction in miRDeep-P2 revolves around the chromosome id, strand direction, mature miRNA sequence, miRNA location, precursor sequence, precursor location, hairpin structure and minimum free energy. Reference genome of sedr had not been sequenced yet. Hence, to predict the novel miRNAs in sedr samples Mirnovo software with default parameters, was used, which is able to identify miRNAs directly from small RNA-seq data with or without reference genome [53].

On the other hand, diet-derived miRNAs in honey bee midgut samples were detected using Bowtie alignment tool with one mismatch allowed. To do this end, clean reads of the honey bee samples were mapped against mature insect miRNAs from miRBase to remove known and conserved insect miRNAs. Unmapped reads to insect miRNAs were aligned against Apis mellifera genome (accession number: GCA_000002195.1) to exclude the reads related to potential novel honey bee miRNAs, which have not been reported yet. Finally, the remaining reads were aligned against the identified sunflower and sedr miRNAs (obtained from the previous steps) to detect diet-derived miRNAs in the midgut tissues.

\section{miRNA target prediction}

To predict the potential targets of the miRNAs of interest, 3'UTR of the annotated genes of honey bee were searched. For genes lacking a predicted 3' UTR, 500 bp downstream of the stop codon was selected as described by [17]. To minimize the false positive results, three different target prediction tools including PITA, Miranda and RNAHybrid were applied with a maximum free energy of $-15 \mathrm{kcal} / \mathrm{mol}$. Those targets that were predicted by two out of the three tools were selected as potential targets of each gene. Kyoto Encyclopedia of Genes and Genome (KEGG) pathway analysis for the target genes of each miRNA was performed using KOBAS 3.0 online 
tool (http://kobas.cbi.pku.edu.cn) and [24]. In addition, corrected $P$-value $<0.1$ was set as the cut-off criterion.

\section{RT-qPCR}

Out of 13 detected plant-derived miRNAs in honey bee midgut, nine miRNAs were randomly selected for further validation using RT-qPCR. The miDETECT A Track Uni-Reverse primers and miDETECT A track miRNA forward primers (specific primers) were used for amplification of the target miRNAs in RT-qPCR (Ribobio CO., Ltd.Guangzhou, China). Poly(A) tailing, reverse transcription and $\mathrm{qPCR}$ were performed successively using the miDETECT A Track miRNA qRT-PCR starter kit (Ribobio Co., Ltd). The RT-qPCR reactions were performed using SYBR green mix in 96 well-plates with two biological replications and three technical replications using Actin (Forward Primer: TGCCAACACTGTCCTT TCTG, Reverse Primer: AGAATTGACCCACCAATC $\mathrm{CA})$ as the endogenous control. The PCR conditions used were as follow: $10 \mathrm{~min}$ at $95^{\circ} \mathrm{C}, 40$ cycles of $2 \mathrm{~s}$ at $95^{\circ} \mathrm{C}, 20 \mathrm{~s}$ at $60^{\circ} \mathrm{C}, 10 \mathrm{~s}$ at $70^{\circ} \mathrm{C}$ and one cycle for melting curve generation. The relative expression level of miRNAs was calculated using CT and $\Delta \mathrm{CT}$ method [54].

\section{Supplementary Information}

The online version contains supplementary material available at https://doi. org/10.1186/s12864-021-07916-4.

\section{Additional file $\mathbf{1}$ Table S1. Identification of known miRNAs in} sunflower pollen. The clean sRNA reads were aligned against the miRBase database which resulted in the identification of 495 shared miRNAs in two samples.

Additional file $\mathbf{2}$ Table S2. Identification of known miRNAs in sedr pollen. The clean sRNA reads were aligned against the miRBase database which resulted in the identification of 423 shared miRNAs in two samples.

Additional file $\mathbf{3}$ Table S3. Identification of novel miRNAs in sunflower pollen. 16 novel miRNAs were predicted in sunflower pollen using miRDeep-P2 software. The predicted miRNAs were belong to 10 families and named as Han-novel-miR100 to Han-novel-miR110.

Additional file 4 Table S4. Identification of novel miRNAs in sedr pollen. Nine novel miRNAs were predicted in sedr pollen using Mirnovo software. miRNAs sequences and theirs coverage features are presented in this table.

Additional file $\mathbf{5}$ Table S5. Detection of sunflower and sedr miRNAs in honey bee midgut. The miRNAs that were detected in both biological replications of each treatment were kept for further analysis. Interestingly, all the identified miRNAs (11 miRNAs in each group) were detected in both biological replications in both plants. Of these miRNAs, nine miRNAs i.e. miR-148a-3p, miR-26a, miR-21-5p, miR-143, miR-27a, miR-203, let-7 g, miR-126, and miR-30d exist in both two groups (honey bee fed with sunflower and sedr pollen). The miR-101 and miR-103 were only detected in honey bees fed with sunflower, while miR-199b-3p and miR-206 were found in honey bees treated with sedr pollen.

Additional file $\mathbf{6}$ Table S6. Target prediction of 11 diet-derived miRNAs in honey bee via PITA, Miranda and RNAHybrid softwares. Those targets that were predicted by two out of the three tools were selected as potential targets of each gene. In total, 121 target genes were predicted for 11 diet derived miRNAs.
Additional file 7 Table S7. KEGG pathway analysis of miR-206 target genes. This miRNA had the highest number of targets with 53 predicted genes. Enrichment analyses of miR-206 target genes indicated target genes participated in 21 different pathways while none of the identified pathways was significant.

\section{Acknowledgments}

We thank Dr. Huamei Xiao for helpful discussions in the experiments. Our appreciation also goes to Feiling Liu, Libin Gao, Qiang Li, Zhenmin Shi, Zhenghong Cao and Kia Liu in Institute of Insect Sciences at Zhejiang University for their support and valuable assistance during this study.

\section{Authors' contributions}

$L G, T H$ and GT designed the research and carried out the field experiments; LG and KH performed RNA extraction and qPCR experiments; LG analyzed and interpreted the data with assistance from MRB, KH and FL; LG wrote the main manuscript; MRB, KH and FL modified the manuscript. All authors have read and approved the manuscript for publication.

\section{Funding}

This study is supported by the National Natural Science Foundation of China (31972354).

\section{Availability of data and materials}

The relevant data and additional information are available in the supplementary files and also from the corresponding author upon reasonable request. Furthermore, the raw small RNA-Seq data were deposited in the NCBI Sequence Read Archive under BioProject number PRJNA695090: https://www.ncbi.nlm.nih.gov/sra/PRJNA695090.

\section{Declarations}

Ethics approval and consent to participate Not applicable.

\section{Consent for publication}

Not applicable.

\section{Competing interests}

The authors have declared that no competing interest exists.

\section{Author details}

'Department of Animal Science, Faculty of Agriculture, University of Zanjan, Zanjan, Iran. ${ }^{2}$ Department of Animal and Poultry Science, College of Aburaihan, University of Tehran, Tehran, Iran. ${ }^{3}$ Ministry of Agriculture and Rural Affairs Key Lab of Molecular Biology of Crop Pathogens and Insects/ Institute of Insect Sciences, Zhejiang University, 866 Yuhangtang Road, Hangzhou 310058, China. ${ }^{4}$ Department of Honeybee, Agricultural Research, Education and Extension Organization (AREEO), Animal Science Research Institute of Iran, Karaj, Iran.

Received: 25 February 2021 Accepted: 22 July 2021

Published online: 03 August 2021

\section{References}

1. Bartel DP. MicroRNAs: genomics, biogenesis, mechanism, and function. Cell. 2004;116(2):281-97. https://doi.org/10.1016/S0092-8674(04)00045-5.

2. Friedman RC, Farh KK, Burge CB, Bartel DP. Most mammalian mRNAs are conserved targets of microRNAs. Genome Res. 2009;19(1):92-105. https:// doi.org/10.1101/gr.082701.108.

3. He L, Hannon GJ. MicroRNAs: small RNAs with a big role in gene regulation. Nat Rev Genet. 2004;5(7):522-31. https://doi.org/10.1038/nrg1379.

4. Tang J, Chu C. MicroRNAs in crop improvement: fine-tuners for complex traits. Nat Plants. 2017;3(7):1-11.

5. Zhang H, Zhang J, Yan J, Gou F, Mao Y, Tang G, et al. Short tandem target mimic rice lines uncover functions of miRNAs in regulating important agronomic traits. PNAS. 2017;114(20):5277-82. https://doi.org/10.1073/pnas.1 703752114. 
6. He K, Xiao H, Sun Y, Situ G, Xi Y, Li F. microRNA-14 as an efficient suppressor to switch off ecdysone production after ecdysis in insects. RNA Biol. 2019; 16(9):1313-25. https://doi.org/10.1080/15476286.2019.1629768.

7. Ye X, Xu L, Li X, He K, Hua H, Cao Z, et al. miR-34 modulates wing polyphenism in planthopper. PLoS Genet. 2019;15(6):e1008235.

8. Ji L, Chen X. Regulation of small RNA stability: methylation and beyond. Cell Res. 2012;22(4):624-36. https://doi.org/10.1038/cr.2012.36.

9. Hunter MP, Ismail N, Zhang X, Aguda BD, Lee EJ, Yu L, et al. Detection of microRNA expression in human peripheral blood microvesicles. PLoS One. 2008;3(11):e3694. https://doi.org/10.1371/journal.pone.0003694.

10. Cocucci E, Racchetti G, Meldolesi J. Shedding microvesicles: artefacts no more. Trends Cell Biol. 2009;19(2):43-51. https://doi.org/10.1016/j.tcb.2008.11.003.

11. Sanchita T. R, Asif MH, Trivedi PK. Dietary plant miRNAs as an augmented therapy: cross-kingdom gene regulation. RNA Biol. 2018;15(12):1433-9. https://doi.org/10.1080/15476286.2018.1551693.

12. Zhang L, Hou D, Chen X, Li D, Zhu L, Zhang Y, et al. Exogenous plant MIR168a specifically targets mammalian LDLRAP1: evidence of crosskingdom regulation by microRNA. Cell Res. 2012;22(1):107-26. https://doi. org/10.1038/cr.2011.158.

13. Ivashuta S, Zhang $Y$, Wiggins BE, Ramaseshadri P, Segers GC, Johnson $S$, et al. Environmental RNAi in herbivorous insects. Rna. 2015;21(5):840-50. https://doi.org/10.1261/rna.048116.114.

14. Wang ZZ, Ye XQ, Shi M, Li F, Wang ZH, Zhou YN, et al. Parasitic insectderived miRNAs modulate host development. Nat Commun. 2018;9(1):1-9.

15. Zhou Z, Li X, Liu J, Dong L, Chen Q, Liu J, et al. Honeysuckle-encoded atypical microRNA2911 directly targets influenza a viruses. Cell Res. 2015; 25(1):39-49. https://doi.org/10.1038/cr.2014.130.

16. Li X, Zhang M, Zhang H. RNA interference of four genes in adult Bactrocera dorsalis by feeding their dsRNAs. PLoS One. 2011;6(3):e17788. https://doi. org/10.1371/journal.pone.0017788.

17. Ashby R, Forêt S, Searle I, Maleszka R. MicroRNAs in honey bee caste determination. Sci Rep. 2016;6(1):1-5.

18. Zhu K, Liu M, Fu Z, Zhou Z, Kong Y, Liang H, et al. Plant microRNAs in larval food regulate honeybee caste development. PLoS Genet. 2017;13(8): e1006946. https://doi.org/10.1371/journal.pgen.1006946.

19. Snow JW, Hale AE, Isaacs SK, Baggish AL, Chan SY. Ineffective delivery of diet-derived microRNAs to recipient animal organisms. RNA Biol. 2013;10(7): 1107-16. https://doi.org/10.4161/rna.24909.

20. Witwer KW, McAlexander MA, Queen SE, Adams RJ. Real-time quantitative PCR and droplet digital PCR for plant miRNAs in mammalian blood provide little evidence for general uptake of dietary miRNAs: limited evidence for general uptake of dietary plant xenomiRs. RNA Biol. 2013;10(7):1080-6. https://doi.org/10.4161/rna.25246.

21. Dickinson B, Zhang Y, Petrick JS, Heck G, Ivashuta S, Marshall WS. Lack of detectable oral bioavailability of plant microRNAs after feeding in mice. Nat Biotechnol. 2013;31(11):965-7. https://doi.org/10.1038/nbt.2737.

22. Masood M, Everett CP, Chan SY, Snow JW. Negligible uptake and transfer of diet-derived pollen microRNAs in adult honey bees. RNA Biol. 2016;13(1): 109-18. https://doi.org/10.1080/15476286.2015.1128063.

23. Bonnet E, Wuyts J, Rouzé P, Van de Peer Y. Evidence that microRNA precursors, unlike other non-coding RNAs, have lower folding free energies than random sequences. Bioinform. 2004;20(17):2911-7. https:/doi.org/10.1093/bioinformatics/bth374.

24. Kanehisa M, Goto S. KEGG: Kyoto encyclopedia of genes and genomes. Nucleic Acids Res. 2000;28(1):27-30. https://doi.org/10.1093/nar/28.1.27.

25. Oliva CA, Montecinos-Oliva C, Inestrosa NC. Wnt signaling in the central nervous system: new insights in health and disease. Prog Mol Biol Transl Sci. 2018;153:81-130. https://doi.org/10.1016/bs.pmbts.2017.11.018.

26. Halder G, Johnson RL. Hippo signaling: growth control and beyond. Develop. 2011;138(1):9-22. https://doi.org/10.1242/dev.045500.

27. Kim K, Kim JH, Kim YH, Hong SE, Lee SH. Pathway profiles based on geneset enrichment analysis in the honey bee Apis mellifera under brood rearing-suppressed conditions. Genomics. 2018;110(1):43-9. https://doi.org/1 0.1016/j.ygeno.2017.08.004

28. Nie H, Liu X, Pan J, Li W, Li Z, Zhang S, et al. Identification of genes related to high royal jelly production in the honey bee (Apis mellifera) using microarray analysis. Genet Mol. 2017:40(4):781-9.

29. Johnston BA, Hooks KB, McKinstry M, Snow JW. Divergent forms of endoplasmic reticulum stress trigger a robust unfolded protein response in honey bees. J Insect Physiol 2016;86:1-0, 10. https://doi.org/10.1016/j.jinsphys.2015.12.004.
30. Zhou G, Zhou Y, Chen X. New insight into inter-kingdom communication: horizontal transfer of mobile small RNAs. Front Microbiol. 2017:8:768. https://doi.org/10.3389/fmicb.2017.00768.

31. Liu H, Wang X, Wang HD, Wu J, Ren J, Meng L, et al. Escherichia coli noncoding RNAs can affect gene expression and physiology of Caenorhabditis elegans. Nat Commun. 2012;3(1):1-1.

32. Weiberg A, Wang M, Lin FM, Zhao H, Zhang Z, Kaloshian I, et al. Fungal small RNAs suppress plant immunity by hijacking host RNA interference pathways. Science. 2013;342(6154):118-23. https://doi.org/10.1126/ science. 1239705.

33. Nowara D, Gay A, Lacomme C, Shaw J, Ridout C, Douchkov D, et al. HIGS: host-induced gene silencing in the obligate biotrophic fungal pathogen Blumeria graminis. Plant Cell. 2010;22(9):3130-41. https://doi.org/10.1105/ tpc. 110.077040.

34. Koch A, Kumar N, Weber L, Keller H, Imani J, Kogel KH. Host-induced gene silencing of cytochrome P450 lanosterol C14a-demethylase-encoding genes confers strong resistance to Fusarium species. PNAS. 2013;110(48): 19324-9. https://doi.org/10.1073/pnas.1306373110.

35. Ghag SB, Shekhawat UK, Ganapathi TR. Host-induced post-transcriptional hairpin RNA-mediated gene silencing of vital fungal genes confers efficient resistance against Fusarium wilt in banana. Plant Biotechnol J. 2014;12(5): 541-53. https://doi.org/10.1111/pbi.12158.

36. Helber N, Wippel K, Sauer N, Schaarschmidt S, Hause B, Requena N. A versatile monosaccharide transporter that operates in the arbuscular mycorrhizal fungus Glomus sp is crucial for the symbiotic relationship with plants. Plant Cell. 2011;23(10):3812-23. https://doi.org/10.1105/tpc.111. 089813.

37. Ibrahim HM, Alkharouf NW, Meyer SL, Aly MA. Abd El Kader Y, Hussein EH, et al. post-transcriptional gene silencing of root-knot nematode in transformed soybean roots. Exp Parasitol. 2011;127(1):90-9. https://doi.org/1 0.1016/j.exppara.2010.06.037.

38. Reinhart BJ, Slack FJ, Basson M, Pasquinelli AE, Bettinger JC, Rougvie AE, et al. The 21-nucleotide let-7 RNA regulates developmental timing in Caenorhabditis elegans. Nature. 2000;403(6772):901-6. https://doi.org/10.103 8/35002607.

39. Sempere LF, Sokol NS, Dubrovsky EB, Berger EM, Ambros V. Temporal regulation of microRNA expression in Drosophila melanogaster mediated by hormonal signals and broad-complex gene activity. Dev Biol. 2003;259(1): 9-18. https://doi.org/10.1016/S0012-1606(03)00208-2.

40. Liu S, Xia Q, Zhao P, Cheng T, Hong K, Xiang Z. Characterization and expression patterns of let-7 microRNA in the silkworm (Bombyx mori). BMC Dev Biol. 2007;7(1):1-7.

41. Behura SK, Whitfield CW. Correlated expression patterns of microRNA genes with age-dependent behavioural changes in honeybee. Insect Mol Biol. 2010;19(4):431-9. https://doi.org/10.1111/j.1365-2583.2010.01010.x.

42. Greenberg JK, Xia J, Zhou X, Thatcher SR, Gu X, Ament SA, et al. Behavioral plasticity in honey bees is associated with differences in brain microRNA transcriptome. Genes Brain Behav. 2012;11(6):660-70. https://doi.org/1 0.1111/j.1601-183X.2012.00782.x.

43. Liu F, Peng W, Li Z, Li W, Li L, Pan J, et al. Next-generation small RNA sequencing for microRNAs profiling in Apis mellifera: comparison between nurses and foragers. Insect Mol Biol. 2012;21(3):297-303. https://doi.org/1 0.1111/j.1365-2583.2012.01135.x.

44. Liu F, Shi T, Qi L, Su X, Wang D, Dong J, et al. IncRNA profile of Apis mellifera and its possible role in behavioural transition from nurses to foragers. BMC Genomics. 2019;20(1):1-1.

45. Ramadan H, Li J. In-Depth Brain Phosphoproteome Study Reveals Neurobiological Underpinnings For Nurse Honeybee Workers (Apis mellifera ligustica). Fayoum J. Agric Res Dev. 2019;33(1):589-07.

46. Fang Y, Feng M, Han B, Lu X, Ramadan H, Li J. In-depth proteomics characterization of embryogenesis of the honey bee worker (Apis mellifera ligustica). Mol Cell Proteomics. 2014;13(9):2306-20. https://doi.org/10.1074/ mcp.M114.037846.

47. Rosales C. Phagocytosis, a cellular immune response in insects. ISJ. 2011;8(1):109-31.

48. Brutscher LM, Daughenbaugh KF, Flenniken ML. Antiviral defense mechanisms in honey bees. Curr Opin Insect Sci. 2015;10:71-82. https://doi. org/10.1016/j.cois.2015.04.016.

49. Zhou W, Li Y, Wang X, Wu L, Wang Y. MiR-206-mediated dynamic mechanism of the mammalian circadian clock. BMC Syst Biol. 2011;5(1):1-7. 
50. Wang Y, Wang Q, Gao L, Zhu B, Ju Z, Luo Y, et al. Parsing the regulatory network between small RNAs and target genes in ethylene pathway in tomato. Front Plant Sci. 2017:8:527.

51. Gruber AR, Lorenz R, Bernhart SH, Neuböck R, Hofacker IL. The vienna RNA websuite. Nucleic Acids Res. 2008;36(suppl_2):W70-4.

52. Kuang $Z$, Wang $Y$, Li L, Yang $X$. miRDeep-P2: accurate and fast analysis of the microRNA transcriptome in plants. Bioinform. 2019;35(14):2521-2. https://doi.org/10.1093/bioinformatics/bty972.

53. Vitsios DM, Kentepozidou E, Quintais L, Benito-Gutiérrez E, van Dongen S, Davis MP, et al. Mirnovo: genome-free prediction of microRNAs from small RNA sequencing data and single-cells using decision forests. Nucleic Acids Res. 2017:45(21):e177.

54. Schmittgen TD, Livak KJ. Analyzing real-time PCR data by the comparative CT method. Nat Protoc. 2008;3(6):1101-8. https://doi.org/10.1038/nprot.2008. 73.

\section{Publisher's Note}

Springer Nature remains neutral with regard to jurisdictional claims in published maps and institutional affiliations.

Ready to submit your research? Choose BMC and benefit from:

- fast, convenient online submission

- thorough peer review by experienced researchers in your field

- rapid publication on acceptance

- support for research data, including large and complex data types

- gold Open Access which fosters wider collaboration and increased citations

- maximum visibility for your research: over $100 \mathrm{M}$ website views per year

At BMC, research is always in progress.

Learn more biomedcentral.com/submissions 